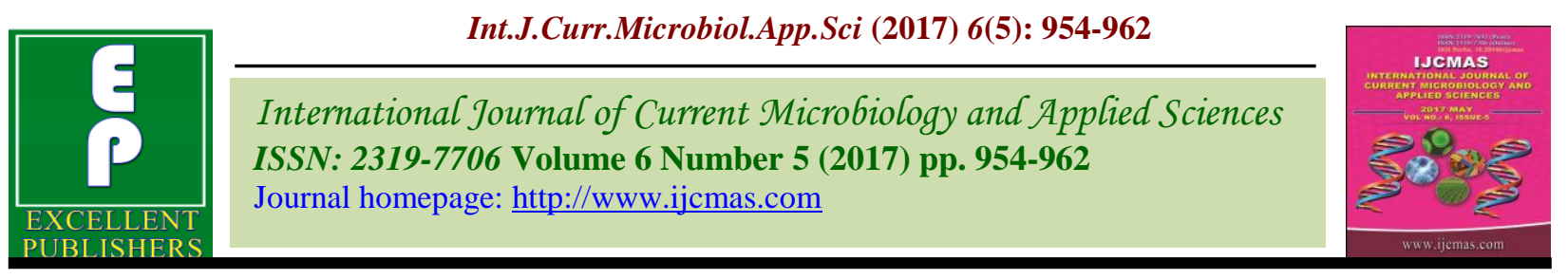

Original Research Article

https://doi.org/10.20546/ijcmas.2017.605.105

\title{
Etiological Spectrum and Prevalence of Acute Undifferentiated Febrile Illness (AUFI) in Fever Cases Attending our Tertiary Care Centre
}

\author{
Gowri Veligandla*, Ezhilvanan, E. Padmavathi and M. Bhaskar \\ Department of Microbiology, Govt. Vellore Medical College, Vellore-11, Tamilnadu, India \\ *Corresponding author:
}

A B S T R A C T

Fever has become a common presenting complaint in the developing world. The symptoms and differential diagnosis of the most common fevers in the tropics that making an accurate clinical diagnosis was difficult without laboratory confirmation. These fevers also lead to high morbidity and mortality. But the exact burden of each

Keywords

Undifferentiated

Febrile Illness

(AUFI), Scrub

typhus,

Leptospirosis.

Article Info

Accepted:

12 April 2017

Available Online:

10 May 2017 infection varies from region to region. Due to high prevalence of local individual diseases the prioritization of the differential diagnosis of a clinical syndrome of acute undifferentiated febrile illness (AUFI) was needed. So the present observational study was conducted among 116 patients to find the etiology, prevalence of AUFI at our tertiary care centre .On admission, after obtaining a detailed history a thorough clinical examination was done to check for symptoms and signs, then the patient's blood and serum sample were collected and various diagnostic tests for Malaria, Dengue, Typhoid, Scrub typhus, Leptospirosis, Chikungunya were done. In our study, Typhoid was the leading cause of AUFI 28(24.14\%), followed by Dengue 12(10.35\%), Malaria $6(5.17 \%)$ and Scrub typhus 2(1.72\%). However 5(4.31\%) cases had Mixed infections. There were almost 63(54.31\%) Undiagnosed infections reported. Another fact in our study was that out of the 116 patients evaluated, 39 (33.6\%) were children of the age group $(0-15)$ years that again invites concern. Hence the present study highlights the need for active surveillance of AUFI, since majority of cases remain undiagnosed there is a need for further research to create a diagnostic algorithm that will aid in timely management of the patients with AUFI.

\section{Introduction}

Every year different parts of India are hit by seasonal fevers especially during the monsoon and post monsoon period between June to September as stated in Susilawati et al., (2014) and Manocha et al., (2004). Acute undifferentiated febrile illness can be differentiated from Fever of unknown origin by fever duration, and progression as described by Phuong et al., (2006).
FUO refers to fever for at least 3 weeks of duration as defined by Petersdorf et al., (1961) and Durrack et al., (1991). The term acute undifferentiated febrile illness (AUFI) connotes fever of $<14$ days duration without any evidence of organ or system specific etiology as described by Rajnishjoshi et al., (2008). With the non-specific clinical presentation of many infections causing AUFI and the limited clinical microbiology services 
available in many low resources areas, very few patients receive an accurate and specific diagnosis and the relative importance of various causes of fever remains unknown at the community level. Nonetheless, the patients admitted to hospitals with fever that is not due to malaria experience case fatality ratios at least as high as those with malaria. The non specificity of the symptoms and signs apart from posing a diagnostic and therapeutic challenge to the treating physician also leads to irrational use of antibiotics and antimalarials as stated by Rajnishjoshi et al., (2008).

According to the systematic review of etiology of Acute undifferentiated fever in Asia(1), Malaria, Dengue, Leptospirosis, Rickettsial infections were frequently identified as causes of Acute undifferentiated fever. Salmonella sp, Escherichia coli, and Staphylococcus aureus were the most common blood culture isolates.

In Tropical countries malaria was frequently suspected as a cause of AUFI and even non malarial cases were treated with antimalarials. But non malarial febrile illness comprised greater proportion of AUFI than malaria in previous studies by Rajnishjoshi et al., (2008), Murdoch et al., (2004), Faruque et al., (2012) and Naing et al., (2012).

A previous study by Singh et al., (2012) showed that climate variation, over population and urbanization may all contribute to the emergence and re-emergence of infections in tropical regions like Tamilnadu.

The prevalence of AUFI varies from region to region. The studies in the table 1 show variation in prevalence of individual diseases with the geographical area and further increase the need for surveillance of AUFI in our tertiary care centre, to avoid over treatment with antibiotics and antimalarials. In limited resource settings fever may be treated empirically or self treated due to lack of access to diagnostic tests. Thus knowledge of local prevalence of infections is critical in order to target clinical work up and treatment as shown in Mittal et al., (2015) and Chaturvedi et al., (2009). Studies from Tamilnadu by Anugrah Chrispal et al., (2010), Rani et al., (2016), Gopalakrishnan et al., (2013) and Kerala by Andrews et al., (2014) showed most of the AUFI are treatable and reduction in mortality if they were diagnosed earlier.

But according to 2014 systematic review, the etiology of 8 to $80 \%$ of cases remain undiagnosed as in Susilawati et al., (2014) which may be due to limited scope of investigations. With this background it was clear that to fill this knowledge gap, surveillance of AUFI was necessary. Hence the present study was planned to augment the early and prompt diagnosis of AUFI and thereby determine the etiology of AUFI in fever cases at our tertiary care centre. In addition the study was designed to determine the prevalence of local infectious diseases causing AUFI in our geographical area.

\section{Materials and Methods}

After obtaining the Institutional Ethical Committee's approval, this observational study was conducted over a period of three months from July 2016 to September 2016 at Government Vellore medical college hospital, a tertiary care centre in Vellore, Tamilnadu, India.

\section{Intervention: None}

\section{Setting}

The Department of Microbiology, Department of Medicine and Department of Paediatrics of our tertiary care hospital which caters to four 
neighbouring districts of Northern Tamilnadu including Vellore, Tiruvannamalai, Kanchipuram and Thirupatthur.

\section{The study population}

All the adults who presented with Acute undifferentiated febrile illness of $<15$ days duration, requiring hospitalization without any localizing signs were included in our study.

All the children who presented with Acute undifferentiated febrile illness of $<15$ days duration, requiring hospitalization without any localizing signs were included in our study.

\section{Sample size}

100 patients (both adult and paediatric age group)

\section{Inclusion criteria}

Both adult and paediatric age group patients presenting with fever for 3 to 15 days duration, with or without maculopapular rash, myalgia, headache, nausea, vomiting, joint pains, body pain, petechiae and eschar who required hospitalisation were included in our study.

\section{Exclusion criteria}

Patients with fever for less than 3 days and with localising signs like respiratory, urinary illness were excluded in our study.

\section{Methods}

On admission, each patient's data was collected after obtaining an informed consent. The detailed history was obtained and clinical examination performed to rule out any local signs. Each patient was clinically evaluated for any rash, petechiae, hydration status, and respiratory distress. Then the patient's serum sample was collected for this study and aliquoted and frozen at -20 degree Celsius. Then Rapid diagnostic test for Malaria (RDT with HRP \& LDH), ELISA for Dengue NSI antigen, IgM ELISA for Dengue, IgM ELISA for Chikungunya, IgM ELISA for Leptospirosis and IgM ELISA for Scrub typhus and coloured antigen based slide agglutination test for diagnosis of enteric fever were done. Other baseline investigations like platelet count, WBC count, hematocrit, peripheral smear were also performed. The data analysis was carried out. Statistical analysis was performed using ' $R$ ' statistical software.

\section{Results and Discussion}

Table 2 shows the Sex wise distribution of etiology of AUFI. In the present study, a total of 116 patients with AUFI were evaluated. Of these $68(58.6 \%)$ were males and $48(41.1 \%)$ were females. In the present study males were affected more than females. The predominance in males may be due to increased chances of exposure to vectors like mosquitoes and contaminated water due to their nature of work. This study was conducted during monsoon period, as it is the most convenient time for breeding of mosquitoes and mites. Drinking water also gets easily contaminated during this period. Seasonal upsurge in fever cases had also been reported in other studies like Murdoch et al., (2004), Jena et al., (2010) and Priyadarshini shanmugam et al., (2016). Adults were the commonly affected group. One study by Abraham et al., (2015) had documented men preponderance with most of the patients in the productive phase of life which correlated with the present study.

Age-wise distribution of these patients in table 3 showed that out of the 116 patients evaluated, $39(33.6 \%)$ were children of the age group (0-15) years, 74(63.7\%) were 
adults of the age-group (16-59)years and $4(3.4 \%)$ patients were senior citizens(> $60 \mathrm{yrs}$ ).Though adults constituted the major affected age group, $33.6 \%$ of the study population comprised of children of the school going age group which demands attention and requires further research.

Table 4 shows Month-wise distribution of etiology of AUFI. The present study was conducted in the monsoon and post monsoon period of three months from July to September. The number of cases were more during the month of August than in July and September.

Table 5 shows the etiological pattern of febrile illness. The study revealed the causes of AUFI as shown in the figure 1. Typhoid was the commonest cause of AUFI in 28(24.14\%) followed by Dengue 12(10.35\%). The present study revealed that Typhoid and Dengue were the common causes of AUFI followed by Malaria 6(5.17\%), and scrub typhus $2(1.72 \%)$, as observed in the previous studies by Thangarasu et al., (2011), Mittal et al., (2015), Singh et al., (2014), Anugrah Chrispal et al., (2010), Rani et al., (2016) and Gopalakrishnan et al., (2013) where the most common causes of AUFI were dengue, Typhoid, Malaria and scrub typhus. In the present study there were $63(54.31 \%)$ patients with undiagnosed febrile illness, their clinical outcomes were studied. All these patients were discharged after they were afebrile for a period of 48 hours with improvement in the general condition. In the present study there was no mortality recorded.

Table 6 shows the pattern of mixed infections. Our study also showed that there were 5 patients with mixed infections (4.31\%). among those with mixed infections $2(1.72 \%)$ had typhoid with malaria, 2(1.7\%) had typhoid with dengue, surprisingly there was 1 patient $(0.9 \%)$ infected with dengue, typhoid and scrub typhus.

In the present study there were no patients diagnosed with leptospirosis, swineflu and chikungunya. Table 7 shows the clinical markers associated with the various causes of AUFI. Typhoid $28(24.14 \%)$ is the major cause of AUFI in our study. Abdominal pain and diarrhoea were most commonly presented symptoms with Typhoid fever. Hepatomegaly and splenomegaly were also commonly reported in these patients.

Dengue is one of the most common causes of AUFI in India and it is documented in many studies from north and south India like Mittal et al., (2015), Singh et al., (2014), Rani et al., (2016), Neelushree et al., (2015). Dengue was identified in 12 cases and it was associated with joint pain, bleeding and thrombocytopenia. Splenomegaly was observed in dengue cases in this study. Unlike other studies such as Gopalakrishnan et al., (2013), there were no associations with rash and petechiae.

Up to $80 \%$ of reported malaria cases in southern/south-eastern Asia are from India, with the majority from states such as Orissa and Andhra Pradesh as mentioned in studies by AnugrahChrispal et al.,.(2010) and Lal et al., (2004). Malaria accounts for $5.17 \%$ of cases and Plasmodium vivax was detected as the causative organism in all cases in this study. Chills, myalgia, and jaundice were the clinical findings associated with malaria in our study. Incidence of Scrub typhus was low in number and also eschar was not seen in the present study. The etiology of majority of cases remains undiagnosed 63(54.31\%) in this study. Similar results were reported in other studies from Tamilnadu by Rani et al., (2016) and Thailand by Leelarasamee et al., (2004). The majority of undiagnosed AUFI may be due to other viral infections. 
Table.1 Shows the prevalence of AUFI in recent studies in India

\begin{tabular}{|c|c|c|c|c|c|c|}
\hline $\begin{array}{l}\text { Author } \\
\text { (Publication } \\
\text { year) } \\
\end{array}$ & $\begin{array}{l}\text { Mittal, Northern } \\
\text { India } \\
\text { 2015(15) }\end{array}$ & $\begin{array}{l}\text { Raginisingh, } \\
\text { Uttarakhand } \\
\text { 2014(16) }\end{array}$ & $\begin{array}{l}\text { Andrews, } \\
\text { Kerala(17) }\end{array}$ & $\begin{array}{l}\text { Chrispal, South } \\
\text { India, Vellore } \\
2010 \text { (18) }\end{array}$ & $\begin{array}{l}\text { Rani, } \\
\text { Salem,Tamiln } \\
\text { adu } \\
2016(19)\end{array}$ & $\begin{array}{l}\text { Gopalakrishnan, } \\
\text { Tamilnadu, } \\
\text { India(20) }\end{array}$ \\
\hline $\begin{array}{l}\text { MOST } \\
\text { COMMON } \\
\text { AUFI }\end{array}$ & $\begin{array}{l}\text { Dengue } \\
(37.54 \%) \text {; Enteric } \\
\text { fever (16.5\%); } \\
\text { Scrub typhus } \\
(14.42 \%) ; \\
\text { Bacterial sepsis } \\
(10.3 \%) \text {; Malaria } \\
(6.8 \%) \text {; Hepatitis } \\
\text { A (1.9\%); } \\
\text { Hepatitis } \\
(1.4 \%) ; \\
\text { Leptospirosis } \\
(0.14 \%) ;\end{array}$ & $\begin{array}{lr}\text { Dengue } & (71.2 \%), \\
\text { Malaria } & (12.8 \%) \\
\text { Typhoid } & (8.1 \%) \\
\text { Scrub typhus }(6.0 \%) \\
\text { Mixed } \\
\text { infection(1.9\%) }\end{array}$ & $\begin{array}{l}\text { Leptospirosis, } \\
\text { Dengue, } \\
\text { Unclassified/ } \\
\text { Miscellaneous } \\
(63.5 \%)\end{array}$ & $\begin{array}{lr}\begin{array}{lr}\text { Scrub } \\
(47.5 \%)\end{array} & \text { typhus } \\
\text { Malaria } & (17.1 \%) \\
\text { Enteric } & \text { fever } \\
(8.0 \%) & \\
\text { Dengue } & (7.0 \%) \\
\text { Leptospirosis } \\
(3 \%) & \\
\text { Unclear } & \text { diagnosis } \\
(8 \%) & \end{array}$ & $\begin{array}{l}\text { Dengue }(27 \%) \\
\text { Typhoid (3\%) } \\
\text { Malaria (2\%) } \\
\text { Rickettsial } \\
\text { infections (1\%) } \\
\text { Others }(67 \%)\end{array}$ & $\begin{array}{l}\text { Malaria }(33 \%) \text {, } \\
\text { Typhoid }(20.59 \%) \text {, } \\
\text { Dengue (10.4\%), } \\
\text { Leptospirosis } \\
(6.2 \%), \\
\text { other causes }(8.9 \%) \\
\text { unknown cause } \\
(20.84 \%) \text {. }\end{array}$ \\
\hline
\end{tabular}

Table.2 Sex wise distribution of etiology of AUFI

\begin{tabular}{|l|l|l|l|l|l|l|l|}
\hline Gender & Typhoid & Dengue & Malaria & $\begin{array}{l}\text { Scrub } \\
\text { typhus }\end{array}$ & $\begin{array}{l}\text { Mixed } \\
\text { infections }\end{array}$ & Others & Total \\
\hline Male & 16 & 5 & 6 & 1 & 4 & 36 & 68 \\
\hline Female & 12 & 7 & 0 & 1 & 1 & 27 & 48 \\
\hline
\end{tabular}

Table.3 Age-wise distribution of etiology of AUFI

\begin{tabular}{|l|l|l|l|l|l|l|l|}
\hline Age group & Typhoid & Dengue & Malaria & $\begin{array}{l}\text { Mixed } \\
\text { infection }\end{array}$ & $\begin{array}{l}\text { Scrub } \\
\text { typhus }\end{array}$ & Others & Total \\
\hline Child 0-15 yrs & 10 & 4 & 1 & & 0 & 24 & 39 \\
\hline $\begin{array}{l}\text { Adult } \\
16-59 \text { yrs }\end{array}$ & 18 & 8 & 5 & 5 & 2 & 36 & 74 \\
\hline Old $>60$ yrs & 0 & 0 & 0 & & 0 & 3 & 3 \\
\hline Total & 28 & 12 & 6 & 5 & 2 & 63 & 116 \\
\hline
\end{tabular}

Table.4 Month-wise distribution of etiology of AUFI

\begin{tabular}{|l|l|l|l|l|l|}
\hline Month & Typhoid & Dengue & Malaria & $\begin{array}{l}\text { Scrub } \\
\text { typhus }\end{array}$ & Others \\
\hline July & 8 & 2 & 2 & 1 & 15 \\
\hline August & 16 & 6 & 4 & 0 & 37 \\
\hline September & 4 & 4 & 0 & 1 & 11 \\
\hline Total & 28 & 12 & 6 & 2 & 63 \\
\hline
\end{tabular}


Table.5 Etiological pattern of febrile illness

\begin{tabular}{|l|l|}
\hline Disease & Incidence \\
\hline Typhoid & $28(24.14 \%)$ \\
\hline Dengue & $12(10.35 \%)$ \\
\hline Malaria & $6(5.17 \%)$ \\
\hline Scrub typhus & $2(1.72 \%)$ \\
\hline Mixed Infection & $5(4.31 \%)$ \\
\hline Undiagnosed & $63(54.31 \%)$ \\
\hline Total & $116(100 \%)$ \\
\hline
\end{tabular}

Table.6 Pattern of mixed infections

\begin{tabular}{|l|l|}
\hline DISEASE & NO. $(\%)$ \\
\hline Typhoid + Dengue & $2(1.7 \%)$ \\
\hline Typhoid + Malaria & $2(1.7 \%)$ \\
\hline $\begin{array}{l}\text { Typhoid + Dengue + Scrub } \\
\text { typhus }\end{array}$ & $1(0.9 \%)$ \\
\hline
\end{tabular}

Table.7 Clinical markers associated with AUFI. [All figures except * are mentioned in percentages; $*$ mentioned as mean $\pm \mathrm{SD}$ ]

\begin{tabular}{|l|l|l|l|l|}
\hline & $\begin{array}{l}\text { Typhoid } \\
(\mathbf{n = 2 8})\end{array}$ & $\begin{array}{l}\text { Dengue(n } \\
\mathbf{1 2})\end{array}$ & $\begin{array}{l}\text { Malaria } \\
(\mathbf{n = 6})\end{array}$ & $\begin{array}{l}\text { Scrub } \\
\text { Typhus } \\
(\mathbf{n = 2})\end{array}$ \\
\hline $\begin{array}{l}\text { Days of } \\
\text { hospitalization }\end{array}$ & $6.3 \pm 2.8$ & $5.9 \pm 2$ & $5.8 \pm 1.3$ & $3 \pm 1.4$ \\
\hline Fever & 100 & 100 & 100 & 100 \\
\hline Abdominal pain & 28.57 & 25 & 0 & 0 \\
\hline Diarrhoea & 17.85 & 8.33 & 0 & 50 \\
\hline Chills & 46.43 & 58.33 & 66.66 & 0 \\
\hline Joint pain & 7.14 & 41.66 & 0 & 0 \\
\hline Myalgia & 50 & 50 & 83.33 & 0 \\
\hline Bleeding & 0 & 16.66 & 0 & 0 \\
\hline Icterus & 0 & 0 & 16.66 & 0 \\
\hline Hepatomegaly & 7.14 & 0 & 0 & 0 \\
\hline Splenomegaly & 7.14 & 8.33 & 0 & 0 \\
\hline Eschar & 0 & 0 & 0 & 0 \\
\hline Haematological finding & 17.86 & 50 & 0 & 0 \\
\hline Thrombocytopenia & \multicolumn{5}{|l|}{} \\
\hline
\end{tabular}


Fig.1 Etiological spectrum of AUFI

\section{Etiological spectrum of AUFI}

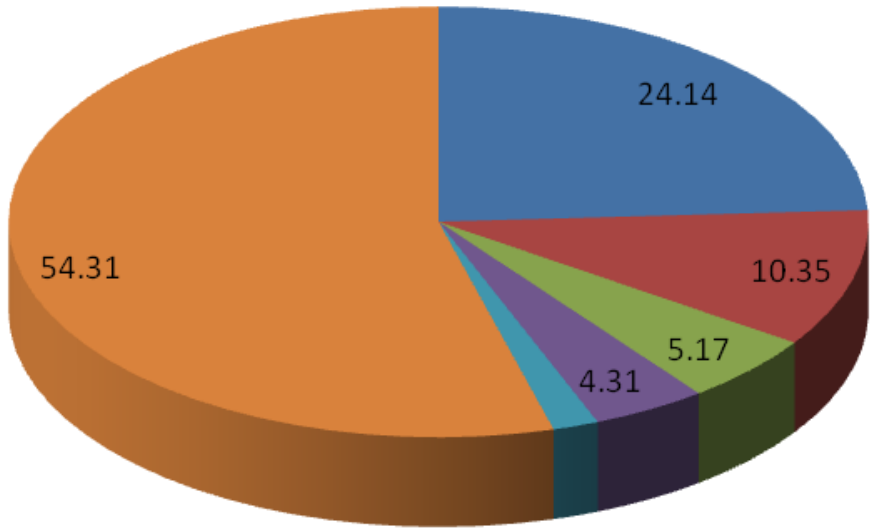

- Typhoid

- Dengue

Malaria

Mixed infections

- Scrub typhus

- Undiagnosed

1.72

The etiology of undiagnosed infections range from $8 \%$ to $80 \%$ as reported in a systematic review of 2014 by Susilawati et al., Mixed infections with more than one etiological agent leads to delay in diagnosis and management due to overlapping of symptoms Mohsin Bin Mushtaq et al., (2013), Suresh et al., (2013), Singhsilarak et al., (2006) and Sharma et al., (2012). Because of this non specificity of symptoms, diagnosis of AUFI is complicated.

In conclusion, the etiology in majority of patients (54.31\%) of AUFI remains unknown. Typhoid, Dengue, Malaria and Scrub typhus were the most commonly indentified diseases in our study. Vector control measures, drinking water supply and sanitation should be improved to prevent vector borne and water borne diseases. Treating physicians should be aware of mixed infections as it may lead to fatal outcomes. As most undiagnosed cases are viral infections symptomatic treatment should be started in patients with suspected viral infections. Clinical diagnosis is not always possible in all the cases, so active AUFI surveillance is necessary for management of febrile patients. Epidemiological database of causes of AUFI is necessary in every region for better health care of the patients. As most of the cases remain undiagnosed further research is needed in designing a Diagnostic algorithm and management of patients with AUFI. The second largest group affected with AUFI in the study population are in the school going age group. So this highlights the need for further research in the incidence prevalence and etiology of paediatric AUFI cases.

\section{Acknowledgement}

I would like to acknowledge ICMR for awarding Short term Student fellowship in the year 2016 to the second author of this project. I would also like to acknowledge the HODs and faculties of Medicine and Paediatrics Department who had extended their cooperation for the completion of this study.

\section{References}

Abraham, M., et al. 2015. Study of acute febrile illness: A 10-year descriptive 
study and a proposed algorithm from a tertiary care referral hospital in rural Kerala in southern India. Trop. Doctor, Vol. 45(2): 114-117.

Andrews, M.A., et al. 2014."Clinical profile of acute undifferentiated febrile illness in patients admitted to a teaching hospital in Kerala."

Anugrah Chrispal et al. 2010. "Acute Undifferentiated Febrile Illness in Adult Hospitalized Patients: The Disease Spectrum and Diagnostic Predictors - an Experience from a Tertiary Care Hospital in South India," Tropical Doctor 40, no. 4 (October 2010): 230 34doi:10.1258/td.2010.100132.

Chaturvedi, H.K., et al. 2009. Treatmentseeking for febrile illness in north-east India: an epidemiological study in the malaria endemic zone. Malar J., 8(1): 301.

Durack, D.T., et al. 1991. Fever of unknown origin - reexamined and redefined. Clin. Top. Infect. Dis., 11: 35-51.

Gopalakrishnan, et al. 2013. "Acute Undifferentiated Febrile Illness Amon Adults-A Hospital Based Observational Study." J. Evol. Med. Dent. Sci., 2, no. 14: 2305-19.

Faruque, L.I., et al. 2012. Hospital-based prevalence of malaria and dengue in febrile patients in Bangladesh. Am. J. Trop. Med. Hyg., 86: 58-64.

Jena, B., et al. 2010. Demand pattern of medical emergency services for infectious diseases in Andhra Pradesh A geo-spatial temporal analysis of fever cases. Indian Emergency J., 1(5): 821.

Jhansi Charles, et al. 2015. Study of Prevalence of Dengue infection in a Rurally situated Tertiary Care Medical College Hospital at Madurai, Tamilnadu. IOSR- J. Dent. Med. Sci., 14(10): 32-36.

Lal, S., Sonal, G.S., Phukan, P.K. 2004. Status of malaria in India. J. Indian
Acad. Clin. Med., 5: 19-23.

Leelarasamee, A., et al. 2004. Aetiologies of acute undifferentiated febrile illness in Thailand. J. Med. Assoc. Thai., 87: 46472.

Malavige, G.N., et al. 2004. Dengue viral infections. Postgrad. Med. J., 80: 588601. doi: 10.1136/pgmj.2004.019638.

Manocha, et al. 2004. Frequency of leptospirosis in patients of acute febrile illness in Uttar Pradesh. J. Assoc. Physicians of India, 52: 623-5.

Mittal, et al. 2015. "Aetiologies of acute undifferentiated febrile illness in adult patients-an experience from a tertiary care hospital in Northern India." J. Clin. Diag. Res., JCDR 9, no. 12, DC22.

Mohsin Bin Mushtaq, et al. 2013. Concurrent Infection with Dengue and Malaria: An Unusual Presentation. Case Reports in Med., doi:10.1155/2013/520181 (Cited on).

Murdoch, D.R., et al. 2004. The etiology of febrile illness in adults presenting to Patan hospital in Kathmandu, Nepal. Am. J. Trop. Med. Hyg., 70: 670-5.

Naing, C., et al. 2012. Scaling-up attention to nonmalaria acute undifferentiated fever. Trans. R. Soc. Trop. Med. Hyg., 106: 331-2.

Neelu Sree, et al. 2015. A pilot styudy on Acute undifferentiated fever using certain rapid microbiological and virology tests. Int. J. Pharm. Bio. Sci., 6(4): 716-723.

Petersdof, R.G., et al. 1961. Fever of unexplained origin: Report on 100 cases. Med., (Baltimore), 40: 1-30.

Phuong, H.L., et al. 2006. Acute undifferentiated fever in Binh Thuan Province, Vietnam: Imprecise clinical diagnosis and irrational pharmacotherapy. Trop. Med. Int. Health, 11: 869-79.

Priyadarshini Shanmugam, et al. 2016. A study on the prevalence of dengue fever 
in Kelambakkam in comparison to an earlier study. Indian J. Microbiol. Res., 3(2): 102-106.

Rajnish Joshi, et al. 2008. Nonmalarial acute undifferentiated fever in a rural hospital in Central India -Diagnostic uncertainity and overtreatment with anti malarial agents. Am. J. Trop. Med. Hyg., 78(3): pp.393-399.

Rani, et al. 2016. "A Study on Common Etiologies of Acute Febrile Illness Detectable by Microbiological Tests in a Tertiary Care Hospital." Int. J. Curr. Microbiol. App. Sci., 5, no. 7: 670-674.

Sharma, A., et al. 2012. Rare Coinfectionof Scrub Typhus and Malaria in Immunocompetent Person. Online $J$. Health Allied Sci., 11(2): 12.

Singh, P.K., et al. 2012. Climate change and human health. J. Vector Borne Dis., 49: 55-60.

Singh, et al. 2014. "A study of etiological pattern in an epidemic of acute febrile illness during monsoon in a tertiary health care institute of Uttarakhand, India." J. Clin. Diag. Res., JCDR, 8, no.
6: $\mathrm{MC} 01$.

Singhsilarak, T., et al. 2006. Possible acute coinfections in thai malaria patients. Southeast Asian J. Trop. Med. Public Health, 37: 1-4.

Suresh, V., et al. 2013. A rare case of triple infection with dengue, malaria and typhoid. Int. J. Res. Dev. Health, Vol 1(4): 200-3.

Susilawati, T.N., et al. 2014. Acute undifferentiated fever in Asia: a review of the literature. The Southeast Asian J. Trop. Med. Public Health, 45(3): 71926.

Suttinont, C., et al. 2006. Causes of acute, undifferentiated, febrile illness in rural Thailand: results of a prospective observational study. Ann. Trop. Med. Parasitol., 100: 363-370. doi: $10.1179 / 136485906 \times 112158$.

Thangarasu, et al. 2011."A protocol for the emergency department management of acute undifferentiated febrile illness in India." Int. J. Emergency Med., 4, no. 1: 1 .

\section{How to cite this article:}

Gowri Veligandla, Ezhilvanan, E. Padmavathi and Bhaskar, M. 2017. Etiological Spectrum and Prevalence of Acute Undifferentiated Febrile Illness (AUFI) in Fever Cases Attending our Tertiary Care Centre. Int.J.Curr.Microbiol.App.Sci. 6(5): 954-962. doi: https://doi.org/10.20546/ijcmas.2017.605.105 